\title{
Isoniazid-resveratrol cocrystal: a novel alternative for topical treatment of cutaneous tuberculosis
}

Juliana Rosa ${ }^{1}$, Tatiane Cogo Machado ${ }^{1}$, Ana Karolina da Silva ${ }^{1}$, Gislaine Kuminek ${ }^{2}$, Adailton João Bortolluzzi ${ }^{3}$, Thiago Caon ${ }^{1 *}$, Simone Gonçalves Cardoso ${ }^{1}$

Supporting information

Table of contents

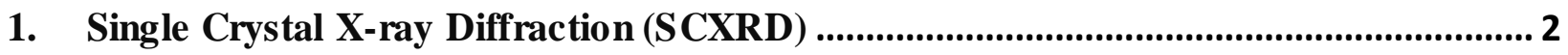

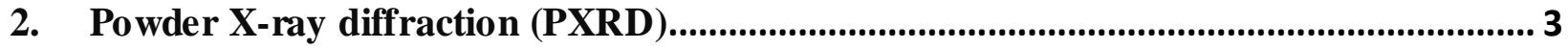

3. Fourier transform infrared (FT-IR) spectroscopy ....................................................... 4

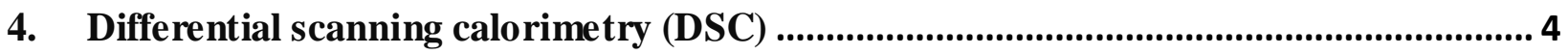

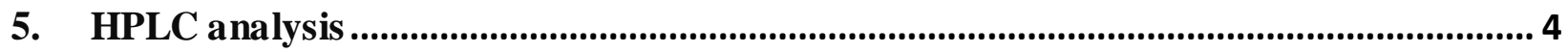

6. INH and RES physical mixture preliminary test........................................................ 5

7. Remaining solid phases of INH-RES cocrystal from donor compartments .................... 6 


\section{Single Crystal X-ray Diffraction (SCXRD)}

X-ray diffraction analysis of the crystals obtained was carried out with a Bruker APEX II DUO diffractometer using graphite-monochromated MoKa radiation (0.71073 $\AA$ ). The temperature of the sample was set at $200( \pm 2) \mathrm{K}$ using an Oxford Instruments Cryojet system 700 series.

Images were recorded by phi and omega scans using APEX2 software ${ }^{1}$. All collected data were corrected for Lorentz, polarization effects and for absorption. The structure was solved by direct methods and refined by full-matrix least-squares on $\mathrm{F}^{2}$ method using SHELXS and SHELXL computational programs ${ }^{2}$, respectively. ORTEP plot was drawn with the PLATON software ${ }^{3}$ (Figure S1). All non-hydrogen atoms were refined with anisotropic displacement parameters. Hydrogen atoms were placed at their idealized positions with distances of $0.95 \AA$ for $\mathrm{C}-\mathrm{H}_{\mathrm{Ar}}$ and their $\mathrm{U}_{\text {iso }}$ values were fixed at 1.2 times the $\mathrm{U}_{\mathrm{eq}}$ of the carrier atom (C). Hydrogen atoms of the $\mathrm{N}-\mathrm{H}$ and $\mathrm{O}-\mathrm{H}$ groups were found from Fourier difference map and treated as free atoms. Full crystallographic tables (including structure factors) for INH-RES have been deposited in the Cambridge Crystallographic Data Centre as supplementary publication numbers CCDC 1854680. These data can be obtained free of charge from the Cambridge Crystallographic Data Centre via www.ccdc.cam.ac.uk. The crystallographic data and refinement details are summarized in Table S1.

Table S1. Experimental details for single crystal structure of INH-RES.

\begin{tabular}{ll}
\hline chemical formula & $\mathrm{C}_{20} \mathrm{H}_{19} \mathrm{~N}_{3} \mathrm{O}_{4}$ \\
formula weight & 365.38 \\
crystallographic system & Orthorhombic \\
space group & $\mathrm{P} 2{ }_{1}{ }_{2}{ }_{1}$ \\
cell parameters $(\AA)$ & $\mathrm{a}=5.1822(3), \mathrm{b}=15.7827(8), \mathrm{c}=21.1257(11)$ \\
volume $\left(\AA^{3}\right)$ & $1727.85(16)$ \\
\hline
\end{tabular}




\begin{tabular}{ll}
\hline calcd density $\left(\mathrm{mg} / \mathrm{m}^{3}\right)$ & 1.405 \\
$\mathrm{Z}$ & 4 \\
abs coeff $\left(\mathrm{mm}^{-1}\right)$ & 0.100 \\
crystal size $\left(\mathrm{mm}^{3}\right)$ & $0.400 \times 0.400 \times 0.400$ \\
$\mathrm{~F}(000)$ & 768 \\
theta range for data collection $\left(^{\circ}\right)$ & 1.928 to 32.641 \\
reflns collected, unique & $15919,6295(\mathrm{R}$ int $=0.0188)$ \\
data / restraints / parameters & $6295 / 0 / 268$ \\
goodness-of-fit on F2 & 0.979 \\
final R indices [I>2 $\sigma(\mathrm{I})]$ & $\mathrm{R} 1=0.0408, \mathrm{wR} 2=0.1037$ \\
$\mathrm{R}$ indices (all data) & $\mathrm{R} 1=0.0499, \mathrm{wR} 2=0.1121$ \\
\hline
\end{tabular}

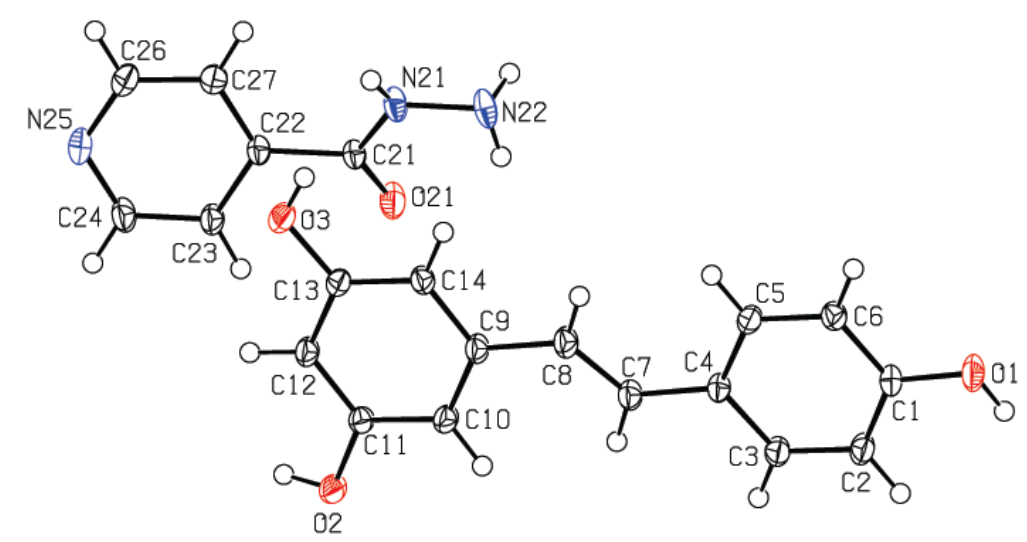

Figure S1. ORTEP diagram of the INH-RES (1:1) cocrystal.

\section{Powder X-ray diffraction (PXRD)}

Powder X-ray diffraction patterns were collected on a $\theta-\theta$ D2 Phaser X-ray diffractometer (Bruker, Karlsruhe, Germany) using $\mathrm{Cu} K \alpha(\lambda=1,5418 \AA$ ) radiation, voltage of $30 \mathrm{kV}$, and a tube current of $10 \mathrm{~mA}$, equipped with a scintillation counter one-dimensional LYNXEYE detector. The intensities were measured at room temperature, with $2 \theta$ angular range from 5 to 
$40^{\circ}$, with a $0.091^{\circ}$ step size. Results were compared to calculated diffraction patterns from crystal structures reported in the Cambridge Structural Database (CSD).

\section{Fourier transform infrared (FT-IR) spectroscopy}

FT-IR spectra were obtained on a Frontier Spectrometer (PerkinElmer, Waltham, U.S.) in a frequency range from 600 to $4000 \mathrm{~cm}^{-1}$ at room temperature. A total of 20 scans were collected for each sample at a resolution of $4 \mathrm{~cm}^{-1}$.

\section{Differential scanning calorimetry (DSC)}

DSC thermograms of cocrystal and raw materials were collected on a Shimadzu DSC-60 module (Kyoto, Japan). Approximately $1.5 \mathrm{mg}$ of samples were placed in hermetically sealed aluminum pans (model 201-52943) and heated from 25 to 200 or $250^{\circ} \mathrm{C}$, at a rate of $10^{\circ} \mathrm{C} /$ min under a nitrogen atmosphere (gas flow rate was set at $100 \mathrm{~mL} / \mathrm{min}$ ). The DSC cell was previously calibrated with indium $\left(\mathrm{T}_{\text {peak }} 156^{\circ} \mathrm{C} ; \Delta \mathrm{H}_{\text {fusion peak }}=28.54 \mathrm{Jg}^{-1}\right)$ and zinc $\left(\mathrm{T}_{\text {peak }} 419^{\circ} \mathrm{C}\right)$. Results were processed in TA-60 software.

\section{HPLC analysis}

INH and RES concentrations were assessed by a Shimadzu LC-10A HPLC system (Kyoto, Japan) equipped with an ultraviolet detector, pump (LC-20ADXR), autosampler (Jasco AS-2055 Plus), solvent degasser (DGU-20A3), and column heater (CTO-20AC). Chromatographic separation was performed at room temperature using a reverse phase $\mathrm{C} 8$ analytical column (Phenomenex Luna ${ }^{\circledR}$ C8, 5 $\mu \mathrm{m}$ x $4.6 \mathrm{~mm}$ x $250 \mathrm{~mm}$ column, Phenomenex ${ }^{\circledR}$, Torrance, EUA). The mobile phase consisted of acetonitrile and water in a ratio of $10 / 90(\mathrm{v} / \mathrm{v})$ and 50/50 (v/v), with 
the detector set at 260 and $306 \mathrm{~nm}$ for INH and RES, respectively. For both analytes, the flow rate was $1 \mathrm{~mL} / \mathrm{min}$, the total sample acquisition time was 6 min and the injection volume was 20 $\mu \mathrm{L}$. The retention time was 3.2 and $3.9 \mathrm{~min}$ for INH and RES, respectively. The quantification methods were validated according to official guidelines ${ }^{4}$. Good linearity was achieved for both INH and RES, $\mathrm{r}^{2}>0.999$ in the range of $1-100 \mu \mathrm{g} / \mathrm{mL}$ for the triplicates of the calibration curves. Intraday and interday precision values $(n=6$ for each component) resulted in acceptable variability (standard deviation below 5\%) for drug and coformer quantification. Accuracy values ranged from 99.6 to $101.3 \%$. The detection and quantification limits were 0.2 and $0.7 \mu \mathrm{g} / \mathrm{mL}$ for $\mathrm{INH}$ and 0.4 and $1.4 \mu \mathrm{g} / \mathrm{mL}$ for RES, respectively.

\section{INH and RES physical mixture preliminary test}

Prior to permeation assays, a preliminary assay to evaluate solid-state transitions mediated by solution was performed by adding a physical mixture of drug and coformer to an Erlenmeyer flask containing $2 \mathrm{~mL}$ PBS buffer at $37^{\circ} \mathrm{C}$. A conversion from drug and coformer physical mixture to cocrystal was detected, as evidenced by the presence of cocrystal characteristic bands at $3354\left(\mathrm{v}_{\mathrm{OH}}\right), 3281,3191\left(\mathrm{v}_{\mathrm{NH} 2}\right), 1640\left(\mathrm{v}_{\mathrm{C}=\mathrm{O}}\right), 1597,1588$ and $1550\left(\delta_{\mathrm{NH} 2}\right)$ after $6 \mathrm{~h}$ under these conditions (Figure S2) ${ }^{5}$. 


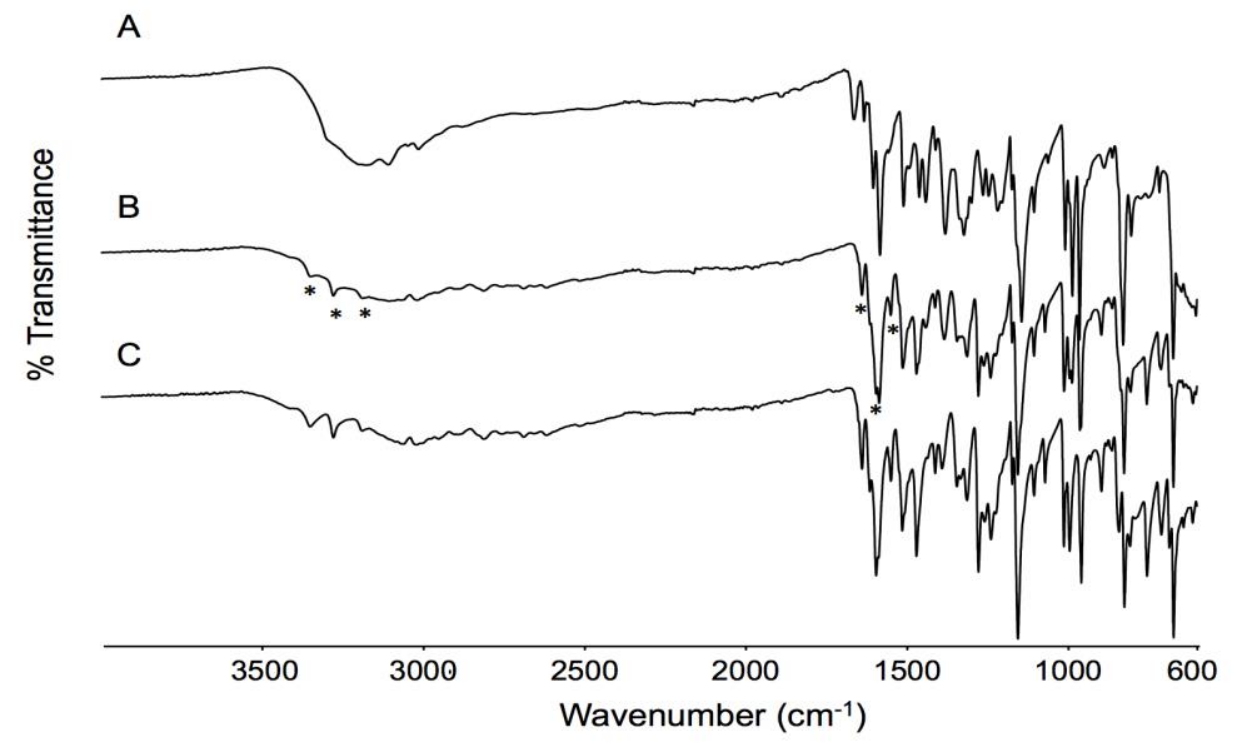

Figure S2. FT-IR spectra of INH: RES (1:1) physical mixture before (A) and after $6 \mathrm{~h}$ in PBS buffer in $\mathrm{pH} 7.4$ (B) showing the conversion to the cocrystal (C). *Represent the major bands of INH-RES cocrystal observed in B.

\section{Remaining solid phases of INH-RES cocrystal from donor compartments}

At the end of the permeation experiments, the remaining solid phases of INH-RES cocrystal from donor compartments were analyzed by PXRD. Figure S3 shows the solid phases were composed by a mixture of INH-RES cocrystal and RES (diffraction peaks at $16.4^{\circ}, 19.2^{\circ}$, and $\left.31.7^{\circ}\right)$. 


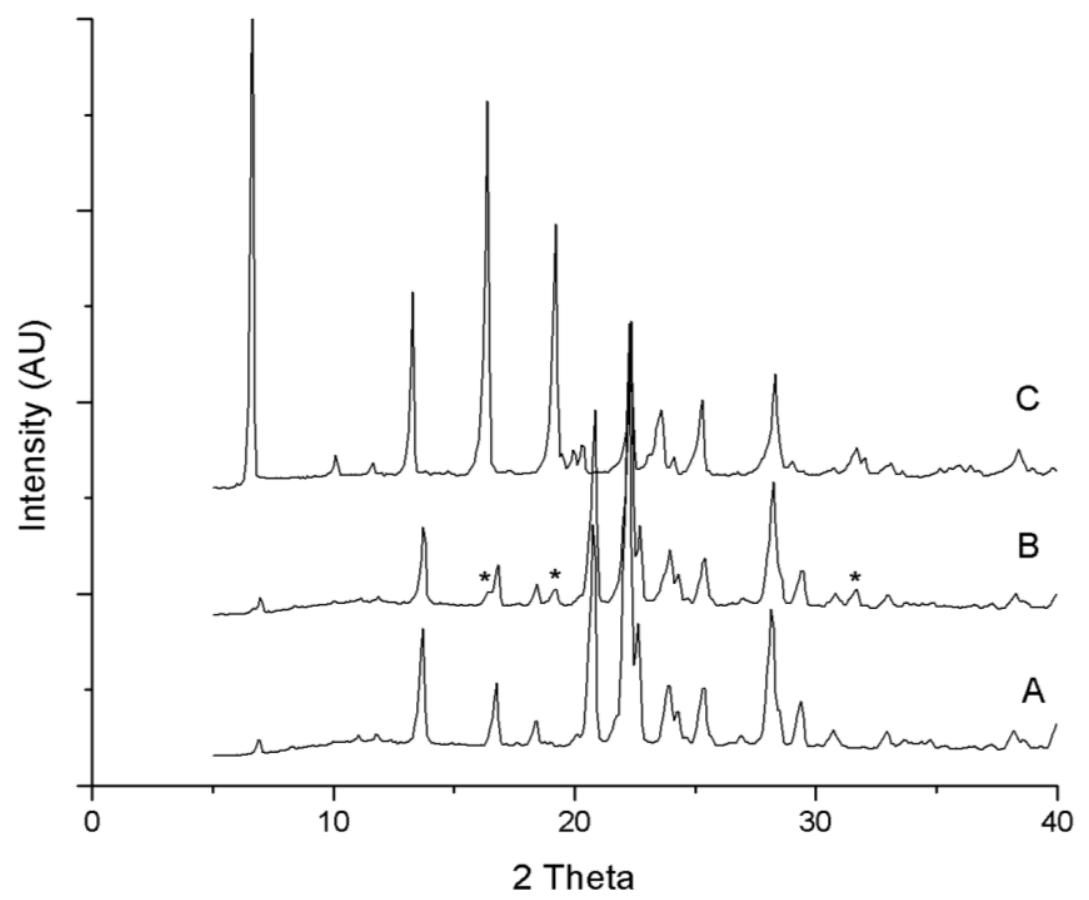

Figure S3. PXRD patterns for INH-RES (A), the solid phase obtained from the donor chamber at the end of permeation assays (B) and RES (C).

*Indicates the diffraction peaks attributed to RES.

\section{References}

(1) Bruker. APEX2, SAINT and SADABS.; Bruker AXS Inc.: Madison, Wisconsin, USA, 2009.

(2) Sheldrick, G. M. A Short History of SHELX. Acta Crystallogr. Sect. A Found. Crystallogr. 2008, 64 (1), 112-122.

(3) Spek, A. L. Structure Validation in Chemical Crystallography. Acta Crystallogr. Sect. D Biol. Crystallogr. 2009, 65 (2), 148-155.

(4) ICH. Validation of Analytical Procedures: Text and Methodology Q2(R1). In International Conference on Harmonization; 2005; pp 1-13.

(5) Zhou, Z.; Li, W.; Sun, W. J.; Lu, T.; Tong, H. H. Y.; Sun, C. C.; Zheng, Y. Resveratrol Cocrystals with Enhanced Solubility and Tabletability. Int. J. Pharm. 2016, 509, 391-399. 